\title{
Oximes in organophosphorus poisoning
}

\author{
M. A. Cherian, ${ }^{1}$ Roshini C,${ }^{2}$ J. V. Peter, ${ }^{3}$ A. M. Cherian ${ }^{4}$
}

Acute organic insecticide poisoning is a major health problem all over the world, particularly in the develop-
ing countries, where organophosphates (OPs) are the most common suicidal poisons with high morbidity
and mortality and account for a large proportion of patients admitted to intensive care units. Other insecti-
cides less commonly used are organocarbamates, organochlorides, and pyrethroids, which are less toxic
and are associated with less morbidity and mortality. Patients with poisoning present with a wide spectrum
of gastrointestinal, neurological, and cardiac manifestations. A strong clinical suspicion is necessary to
make an early diagnosis and to start appropriate therapy. Treatment is primarily supportive and includes
decontamination, anticholinergics, protection of the airway, and cardiac and respiratory support. The use of
oximes has been controversial and may be associated with higher mortality owing to a higher incidence of
type-Il paralysis. They may have other toxic side effects. This paper reviews the literature on OP poisoning.
Key Words: Anticholinergics, Manifestations, Organophosphate, Oximes, Poisoning

\section{Introduction}

Organophosphate (OP) compounds have been used worldwide for pest control for over 100 years. They are the insecticides of choice in the agricultural world and are the most common cause of poisoning among the organic insecticides. They are common agents of suicidal and accidental poisoning, as a result of their ready availability and easy accessibility. Several hundred people around the world die each year from OP poisoning, especially in developing countries. ${ }^{[1]}$ Recently, there has been a renewed interest in OP compounds as these are agents which might be used as chemical weapons.

The WHO estimates that three million cases of poisoning occur worldwide, mostly in the developing coun-

'Merit Care/UND Program, MeritCare Medical Group, Fargo, ND 58122,USA.

${ }^{2}$ Launceston General Hospital, Launceston, Tasmania, Australia.

${ }^{3}$ The Queen Elizabeth Hospital, Adelaide, S.A 5011, Australia.

${ }^{4}$ Department of Medicine, TMM Hospital, Tiruvalla 689101, India.

Correspondence:

Dr. A. M. Cherian, TMM Hospital, Tiruvalla 689101, Kerala, India.

E-mail: amcherian@hotmail.com
}

tries. ${ }^{[2]}$ There has been a change in the type of agents used for suicide attempts, with OP poisoning being seen more and more frequently as compared with phenobarbitone, diazepam, hypnotics, and antidepressants a couple of decades ago. In the Christian Medical College (CMC) and Hospital, Vellore, India, OP poisoning accounted for $12 \%$ of all admissions to the medical intensive care unit (ICU) and $29 \%$ of all poisoning in the early $1990 \mathrm{~s}^{[3]}$ and now accounts for over $70 \%$ of all poisonings. In another center $89.75 \%$ of patients admitted with poisoning were owing to OP..$^{[4]}$ OP compounds are common suicidal agents in Pakistan, ${ }^{[5]}$ Sri Lanka, ${ }^{[6]}$ and the other Asian and South East Asian countries.

The OP compounds are popular insecticides because of their effectiveness and nonpersistence in the environment owing to their unstable chemical nature. They do not persist in the body or environment as do organochlorides and have become the insecticide group of choice replacing DDT, an organochloride compound..$^{[7]}$

OPs are common household insecticides used exten-

Free full text available from www.ijccm.org 
sively by agricultural communities. Seasonal variations in water availability keep these communities in financial debt, driving farmers to suicide by ingestion of agricultural pesticides that are sold directly over the counter and have inadequate regulations controlling their use and storage. Early and correct diagnosis and treatment may be life-saving in OP poisoning. It is important to treat cases in hospitals with respiratory support facilities to reduce the morbidity and mortality.

\section{Historical Perspective}

The first OP compound synthesized in 1854 was tetraethyl pyrophosphate (TEPP). It came into use in Germany during World War II as an agricultural pesticide substitute for nicotine and for possible use as a nerve gas in chemical warfare. It is also the most toxic of the OP insecticides. ${ }^{[8]}$ Parathion, an organic derivative of phosphoric acid, was synthesized shortly after World War II. Because it has to be converted to paraoxon by substitution of oxygen for sulfur to be physiologically active, symptoms of parathion intoxication are often delayed for 6-24 h. There have been numerous OP compounds synthesized over the years and over a hundred compounds are currently available under different brand names, making identification difficult in a given patient, unless the container is brought in by the patient's relative. Of the OP group, Parathion is the most common cause of human poisoning and fatality. ${ }^{[9]}$

\section{Pharmacology}

The OP compounds are classified in many ways; one based on clinical toxicity is as follows: ${ }^{[9]}$

1. Agricultural insecticides (high toxicity), for example, TEPP, parathion, phorate, mevinphos, and disulfoton.

2. Animal insecticides (intermediate toxicity), for example, coumaphos, chlorpyrifos, trichlorfon, and ronnel.

3. Household use or use in golf courses (low toxicity), for example, diazinon, malathion, dichlorvos, and acephate.

OPs may also be classified according to their pharmacokinetics as given below.

\section{Pharmacokinetics}

The onset, intensity, and duration of pharmacological effects that occur after poisoning are determined largely by the factors listed in Table 1.
Most OPs are well absorbed from skin, oral mucous membranes, conjunctival mucous membrane, and gastrointestinal and respiratory routes. Subsequently, most OP compounds are hydrolyzed by enzymes, the A esterases or paroxonases, which are not inhibited by OP compounds. These enzymes are found in the plasma and in the hepatic endoplasmic reticulum and split the anhydride, $\mathrm{P}-\mathrm{F}, \mathrm{P}-\mathrm{CN}$, or ester bonds. ${ }^{[10]}$ The metabolic products are then excreted in the urine. OP compounds that bind to acetylcholinesterase block the conversion of acetylcholine to its degradation products, namely, acetic acid and choline. This leads to a build-up of excessive acetylcholine at synapses, which is the primary cause of most of the toxic effects of OP compounds.

\section{Pathophysiology of OP Poisoning}

Acetylcholine is the neurotransmitter released by the terminal nerve endings of all postganglionic parasympathetic nerves and in both sympathetic and parasympathetic ganglia. It is also released at the skeletal myoneural junctions and serves as a neurotransmitter in the central nervous system. ${ }^{[11]}$ Acetylcholinesterase is present in two forms: true cholinesterase which is found primarily in the nervous tissue and erythrocytes and pseudocholinesterase which is found in the serum and liver. ${ }^{[9]}$ OPs bind to the active serine residue of acetyl cholinesterase irreversibly and convert the enzyme into

Table 1: Factors determining the onset, duration, and intensity of OP poisoning

\begin{tabular}{|c|c|}
\hline Nature of compound & Remarks \\
\hline Water-soluble & $\begin{array}{l}\text { Acute and shorter duration of } \\
\text { symptoms, e.g., TEPP }\end{array}$ \\
\hline Lipid-soluble & $\begin{array}{l}\text { Delayed and more sustained } \\
\text { effect, e.g., chlorfenthion }\end{array}$ \\
\hline \multicolumn{2}{|l|}{ Nature of binding } \\
\hline Reversible & Short-lived effects \\
\hline Irreversible & Persistent effects, e.g., parathion \\
\hline \multicolumn{2}{|l|}{ Mode of action } \\
\hline Direct agent & $\begin{array}{l}\text { Direct acetyl cholinesterase } \\
\text { inhibition, e.g., sarin }\end{array}$ \\
\hline Indirect agent & $\begin{array}{l}\text { Needs to be converted to active } \\
\text { metabolite, e.g., parathion }\end{array}$ \\
\hline \multicolumn{2}{|l|}{ Route/degree of exposure } \\
\hline Cutaneous & Chronic toxicity \\
\hline Oral/GIT & Acute symptoms \\
\hline Inhaled & $\begin{array}{l}\text { May be acute or chronic } \\
\text { depending on poison load }\end{array}$ \\
\hline \multicolumn{2}{|c|}{ Relative toxicity of the compound } \\
\hline \multicolumn{2}{|l|}{ Low } \\
\hline \multicolumn{2}{|l|}{ Intermediate } \\
\hline \multicolumn{2}{|l|}{ High } \\
\hline $\begin{array}{l}\text { Rate of metabolic degradation } \\
\text { Malathion }\end{array}$ & \\
\hline
\end{tabular}


an inactive protein complex, resulting in the accumulation of acetylcholine at the receptors, leading to overstimulation and subsequent disruption of nerve impulse transmission in both the peripheral and central nervous systems.

\section{Etiology of OP Poisoning}

OP poisoning results either from suicidal or accidental poisoning or from occupational exposure such as farming. A large proportion (68\%) of patients presented to the ICU following an acute suicide attempt. ${ }^{[6,8]}$ Most patients are young (less than 30 years) with a male preponderance..$^{\left[{ }^{812]}\right.}$ Occupational and accidental poisoning occur less commonly in India. ${ }^{[8]}$

\section{Clinical Features of Poisoning}

Clinical features of acute poisoning occur within $24 \mathrm{~h}$ of ingestion of the OP compound. These can be broadly classified as follows.

\section{Muscuranic Effects}

Cardiovascular: Bradycardia, hypotension.

Respiratory: Rhinorrhea, bronchorrhea, bronchospasm, cough.

Gastrointestinal: Increased salivation, nausea and vomiting, abdominal pain, diarrhea, fecal incontinence.

Genitourinary: Urinary incontinence.

Ocular: Blurred vision, increased lacrimation, miosis.

Dermatologic: Excessive sweating.

\section{Nicotinic Effects}

Cardiovascular: Tachycardia, hypotension.

Musculoskeletal: Weakness, fasciculations, cramps, paralysis.

\section{Central Receptor Stimulation}

Anxiety, restlessness, ataxia, absent reflexes, convulsions, insomnia, tremors, dysarthria, coma, hyperreflexia, Cheyne Stokes breathing, respiratory depression, and circulatory collapse come under this. ${ }^{[13]}$

The end-result may be multisystem manifestations in volving the gastrointestinal tract, respiratory system, cardiovascular system, nervous system, skeletal muscles, as well as metabolic effects such as hypo- or hyperglycemia.

\section{Neurological Manifestations in OP Poisoning}

Neurological manifestations are the most important sequelae of OP poisoning as a large number of patients with acute OP poisoning develop neuromuscular weakness requiring prolonged ventilation. Three types of paralyses are recognized based on the time of occurrence and differ in their pathophysiology.

\section{Type-I Paralysis or Acute Paralysis}

Type-I paralysis occurs with the initial cholinergic crisis. This is postulated to be owing to the persistent depolarization at the neuromuscular junction resulting from blockade of acetylcholinesterase, and usually develops within 24-48 h. Features include muscle fasciculations, cramps, twitching, and weakness. These manifestations respond to atropine ${ }^{[14]}$ although it may not fully block the nicotinic effects. Muscle weakness may have upper motor neuron manifestations. Muscle paralysis may also involve the respiratory muscles, leading to respiratory failure, requiring ventilation. This may be further compounded by severe bronchorrhea. Acute respiratory failure has been observed in $33 \%$ of patients who presented with OP poisoning. ${ }^{[15]}$

\section{Type-II Paralysis or Intermediate Syndrome}

This was first described by Wadia as Type-II paralysis $^{[16]}$ and subsequently described and termed as intermediate syndrome by Senanayake. ${ }^{[17]}$ Since then, there have been numerous reports of this syndrome. ${ }^{[14,18-21]}$ It is a clinical entity that develops after the acute cholinergic crisis, 24-96 $\mathrm{h}$ after the poisoning. In the majority of patients, respiratory insufficiency draws attention to the onset of the syndrome. Cranial nerve palsies and proximal muscle weakness are observed. There is relative sparing of the distal muscle groups. The reported incidence of this syndrome varies between $8 \%$ and $49 \% .{ }^{[20-}$ 22]

One of the earliest manifestations in these patients is the presence of marked weakness of neck flexon with the inability to lift the head from the pillow. This is a reliable test to assess if a patient is likely to develop respiratory muscle weakness and to pre-emptively manage respiratory embarrassment. The common cranial nerves involved are those supplying the extraocular muscles. 
Cranial nerves VII and $X$ are less frequently affected. Electromyographic (EMG) studies have shown a combination of pre- and postsynaptic dysfunction of neuromuscular transmission. Senanayake showed a fade on tetanic stimulation and absence of post-tetanic facilitation. ${ }^{[17]}$ Nerve conduction and EMG studies in our cohort of patients have shown that the primary type of involvement is an axonal neuropathy. ${ }^{[23]}$ In addition to the neuromuscular transmission defect, anterior cell or toxininduced muscular instability appear to play a role in TypeIl paralysis. This syndrome persists for approx 4-18 days and most patients survive this with ventilatory support unless infections complicate the course. More studies from CMC, Vellore, have shown that there is a myopathy as evidenced by significant elevation of muscle enzymes. ${ }^{[24]}$

\section{Type-III Paralysis or OP-Induced Delayed Polyneu- ropathy}

OP-induced delayed polyneuropathy (OPIDP) is a sensory-motor distal axonopathy that usually occurs after the ingestion of large doses of certain OP insecticides ${ }^{[25-}$ 27] or after chronic exposure. Two distinct clinical entities have been described, one being pure motor polyneuropathy and the other having a mild sensory component with a more prominent motor component. A pure sensory neuropathy has not been observed in either single or repeated acute OP poisoning. ${ }^{[25]}$ Unlike the intermediate syndrome, it usually occurs 2-3 weeks after the acute poisoning episode and is characterized by distal muscle weakness with sparing of neck muscles, cranial nerves, and proximal muscles. The EMG features are those of denervation and recovery is delayed for up to 6-12 months. High-dose methyl prednisolone has been shown to be beneficial in animal studies. ${ }^{[28]}$

\section{Other Neurologic Manifestations}

Various neuropsychiatric manifestations have been described, especially in chronic poisoning. ${ }^{[29]}$ These have been termed as chronic OP-induced neuropsychiatric disorder, and includes impaired memory, confusion, irritability, lethargy, and psychosis. These manifestations are usually temporary. Extrapyramidal manifestations have also been reported in acute poisoning, developing for 4-40 days following poisoning and lasting for approx 1-4 weeks, including dystonias, resting tremor, cogwheel rigidity, and choreoathetosis. ${ }^{[30]}$ Neuro-ophthalmological sequlae have been documented after chronic environmental exposure including optic atrophy, degeneration of retina, defective vertical smooth pursuit movements, myopia owing to spasm, or paresis of accommodation. ${ }^{[31]}$ Rare neurological manifestations include Guillian-Barré syndrome, ${ }^{\left[{ }^{[32]}\right.}$ sphincter involvement, ${ }^{[33]}$ isolated bilateral recurrent laryngeal nerve paralysis, ${ }^{[34]}$ and ototoxicity. ${ }^{[35]}$

\section{Cadiovascular Manifestations}

Cardiac manifestations are often the cause of serious complications or fatality. A systematic analysis of patients with poisoning showed a wide variety of cardiac manifestations. ${ }^{[36]}$

\section{Electrocardiographic Manifestations}

These include prolonged Q-T corrected (QTc) interval (67\%); elevated ST segment (24\%); inverted T-waves (17\%); prolonged PR interval (9\%); rhythm abnormalities such as sinus tachycardia (35\%), sinus bradycardia $(28 \%)$, extra systoles $(6 \%)$, atrial fibrillation $(9 \%)$, ventricular tachycardia (4\%); and other manifestations such as noncardiogenic pulmonary edema (43\%), hypertension (22\%), and hypotension (17\%).

Ludomirsky et al. ${ }^{[37]}$ described three phases of cardiac toxicity.

Phase 1: A brief period of increased sympathetic tone.

Phase 2: Prolonged period of increased parasympathetic activity, including atrioventricular block.

Phase 3: QT prolongation followed by torsade de points, ventricular tachycardia, and development of ventricular fibrillation.

A picture similar to myocardial infarction has also been reported. ${ }^{[38]}$ In a recent study QTc prolongation at admission was found to be associated with respiratory failure and higher mortality. ${ }^{[39]}$ The mechanism of cardiac toxicity includes a direct toxic effect on the myocardium, overactivity of cholinergic or nicotinic receptors, hypoxemia, acidosis, electrolyte abnormalities, and highdose atropine therapy.

\section{Respiratory Manifestations}

In the acute phase, muscarinic effects of bronchorrhea, bronchospasm, and laryngeal spasm can result in airway obstruction. The nicotinic effects lead to weakness and paralysis of the respiratory and the oropharyngeal 
muscles. Central depression of respiration owing to involvement of cholinergic systems in the brainstem finally leads to respiratory arrest. ${ }^{[15]}$

Acute respiratory failure (less than $24 \mathrm{~h}$ ) was seen in $33 \%$ of patients with acute poisoning. ${ }^{[17]}$ Most patients with intermediate syndrome develop respiratory failure, which requires mechanical ventilation. ${ }^{[15,17]}$

\section{Gastrointestinal Manifestations}

GI manifestations are the first to appear, and they respond well to atropine therapy. Rarely, acute pancreatitis has been reported. ${ }^{[40,41]}$ Patients may also have hypoor hyperglycemia. ${ }^{[42]}$

\section{Grading the Severity of OP Poisoning}

Various grading methods are available and these are helpful in grading severity and in the management of the syndrome. ${ }^{[43,44]}$ We have found, however, that these do not always correlate with outcomes. Some patients who appear to recover $24 \mathrm{~h}$ later develop intermediate syndrome.

\section{Diagnosis}

The diagnosis of OP poisoning is made primarily based on the history and a combination of clinical features, including the typical odour of the insecticide. Some patients may present with nicotinic effects of tachycardia and mydriasis rather than the anticipated bradycardia and miosis. Some poison centers can identify the compound from the stomach contents.

\section{Cholinesterase Estimation}

True and pseudocholinesterase levels can be estimated. The levels are markedly reduced in OP poisoning. Although true cholinesterase levels correlate with severity at presentation, pseudocholinesterase levels do not. ${ }^{[45]}$ Serial estimations do not correlate with clinical improvement, and hence these tests are to be used primarily to confirm the diagnosis. Other causes of lowserum cholinesterase include parenchymal liver disease, congestive cardiac failure with hepatomegaly, metastatic carcinoma, malnutrition, dermatomyositis, and acute infection. A $25 \%$ or greater depression in red-blood-cell cholinesterase level is taken as the best indicator of OP poisoning. ${ }^{[9]}$

\section{Management}

Treatment should be initiated immediately on clinical grounds without waiting for blood investigations.

\section{General Measures}

\section{Decontamination}

Decontamination of the skin is very important and it should be done very thoroughly. The patient should be stripped and washed with soap and water and then with ethyl alcohol. This will prevent further absorption through the skin. Health-care personnel should wear protective clothing and glasses.

Gastric decontamination should be done by forced emesis if the patient is fully awake or through a gastric lavage. All patients should also receive $0.5-1 \mathrm{~g} / \mathrm{kg}$ activated charcoal every $4 \mathrm{~h}$. Sodium sulfate or sorbitol can be used as a cathartic. A recent study has shown that the addition of serotonin adipinate, a drug that enhances the propulsive function of the gastrointestinal tract, resulted in a shortening of the toxicogenic phase and a 3.5 -fold reduction of mortality. ${ }^{[46]}$

\section{Airway and Respiration}

The airway should be secured and adequate oxygenation should be ensured. Atropine can precipitate ventricular arrhythmia in hypoxic patients. On the other hand, early use of atropine will reduce respiratory secretions, improve muscle weakness, and thereby improve oxygenation. Careful observation of the respiratory status is required as these patients are prone to respiratory failure during the acute phase and intermediate syndrome. The important parameters to be monitored on a regular basis are (a) symptoms of ocular muscle involvement (e.g.; diplopia), (b) neck muscle weakness, (c) respiratory rate, (d) tidal volume or vital capacity, (e) single breath count, and (f) arterial blood gas estimation or pulse oximetry. Respiratory infections should be anticipated and treated appropriately. Theophylline is contraindicated in the management of OP poisoning. ${ }^{[9]}$

\section{Cardiac Monitoring}

Wide-ranging cardiac manifestations occur, and careful hemodynamic and electrocardiographic monitoring should be undertaken. Hypoxemia and electrolyte abnormalities contribute to cardiac complications. Some 
of these may revert with atropine. Ventricular tachycardia with a prolonged QTc is best treated with electrical pacing. ${ }^{[39]}$ Supraventricular tachycardia can be treated with an IV bolus of short-acting â-blockers.

\section{Anticholinergic Agents}

\section{Specific Therapy}

Anticholinergics are still the mainstay of treatment and should be started as soon as the airway has been secured. Atropine can be started initially as a 2-mg intraventricular (IV) bolus and then at doses of $2-5 \mathrm{mg}$ IV bolus every $5-15$ min until atropinization is achieved. The atropine dose in children is $0.05 \mathrm{mg} / \mathrm{kg}$ IV with a maintenance dose ranging from 0.02 to $0.05 \mathrm{mg} / \mathrm{kg}^{\left[{ }^{[9]}\right.} \mathrm{It}$ is important to monitor these patients closely to prevent atropine toxicity and have clear end-points for atropinization. Contrary to earlier beliefs, it is no longer necessary to achieve total atropinization (i.e., full mydriasis, heart rate more than 150/min, and absent bowel sounds). In our experience a dose which keeps the heart rate at approx 100/min, pupils' midsize, and bowel sounds just present, maintains adequately atropinization without the risks of hyperexcitability, restlessness, hyperpyrexia and cardiac complications that are seen with total atropinization. Some uncontrolled studies have shown that an atropine infusion, as opposed to bolus doses at intervals, reduces mortality. ${ }^{[47]}$ Bardin and Van Eden ${ }^{[44]}$ have demonstrated that glycopyrrolate is equally effective with less central nervous system side effects and better control of secretions. The dose of atropine required is maximal on day 1 and tends to decrease over the next few days. The mean total dose of atropine in our series has been 140-167 mg. ${ }^{[48]}$ Atropine does not reverse the effects of intermediate and Type-III paralysis.

\section{Oximes}

Oximes are nucleophilic agents that are known to reactivate the phosphorylated acetylcholinesterase by binding to the organophosphorus molecule. ${ }^{[10]}$ The use of oximes in acute OP poisoning has been a controversial subject for over two decades. Initial uncontrolled studies suggested that oximes (pralidoxime, P2AM) were useful in the routine management of OP poisoning. ${ }^{[49,50]}$ A subsequent report by de Silva et al., ${ }^{[51]}$ studying two periods of time (one when P2AM was available in their country and another when it was unavailable), found that P2AM did not make any difference to the outcomes. Recently, there have been a number of studies on the pharmacokinetics of these compounds and different oximes used, but these predominantly consisted of in vitro studies. A few in vivo studies, animal studies, and a few case series also exist. Reactivation has been shown to be complete when oximes are given within $1 \mathrm{~h}$ of exposure. ${ }^{[52]}$ Its effects are different in different species, ${ }^{[53]}$ and different with different OP compounds. ${ }^{[54]}$ There is also variability in their potency with $\mathrm{pH}$ and temperature. The rate and magnitude of aging of the enzyme is also different with different OP compounds. ${ }^{[55,56]}$ Once aging of the enzyme-OP complex has occurred, reactivation of the enzyme is not possible.

None of the oximes (pralidoxime, obidoxime, HI6, and Hlo7) are considered to be universal reactivators. Some are of broader spectrum and the potencies also differ. Obidoxime is the most potent with some OP compounds and $\mathrm{HI} 6$ against others. ${ }^{[55]}$ Pralidoxime is generally less potent. ${ }^{[54-56]}$ Studies have shown that obidoxime is forty, nine, and three times more potent than HI6, Hlo7, and pralidoxime, respectively. ${ }^{[55]}$ Other studies have shown that $\mathrm{Hlo} 7$ is superior to the other oximes. ${ }^{[56]}$

Administration is an important issue, as only the powder form is stable, and once diluted, the oximes lose their potency. ${ }^{[57]}$ An autoinjector that can dissolve the powder for the purpose of IM injection before admission to the hospital has also been recommended. However, in megadose poisoning, even a high dose of oxime may not be effective in reactivating the enzyme in the first few days following poisoning. ${ }^{[57]}$ At least in three studies oximes have been effective when the poisoning severity was mild. ${ }^{[52,55,58]}$ Cycloserin has been shown to be resistant to oxime therapy. ${ }^{[57]}$ It is also possible that the response to P2AM may be different for the direct as opposed to the indirect anticholinesterase agents.

In some studies formation of methemoglobin and cyanide have been shown after IV administration of oximes to dogs especially with impaired renal function. ${ }^{[56,57,59]}$ Obidoxime also leads to hepatotoxicity. ${ }^{[52]}$ The reports are conflicting, though a lot work is being done in this field. Pralidoxime is the oxime available in India, is very expensive, and the least potent of all oximes.

A Medline search revealed only few randomized, controlled studies. ${ }^{[3,20,48,60,61]}$ In a small, recent study, respiratory complications were more in the group treated with 
obidoxime or P2AM. ${ }^{[62]}$ Mortality was 9\% (4/43) in the group treated with atropine, $50 \%(6 / 12)$ in the group treated with obidoxime and atropine, and there was no mortality in the group treated with P2AM (eight patients). Another study, small but randomized, showed that P2AM had no effect in moderate and severe poisoning. ${ }^{[63]}$

We did two major randomized, controlled studies with similar protocols using $12 \mathrm{~g}$ of P2AM infusion over 3 days. The first was $12 \mathrm{~g}$ infusion over 4 days $v s 1 \mathrm{~g}$ at admission and the second was $12 \mathrm{~g}$ infusion over 4 days vs placebo. ${ }^{[3,48,60]} \mathrm{A}$ higher mortality was observed in the P2AM group in both the studies. Ventilatory requirement and incidence of intermediate syndrome was higher in the treatment group. Similar results were found when the two studies were pooled. ${ }^{[64]}$ Also, a dose-response relationship was shown, especially with a higher sample size, when the two studies were pooled together (Table 2). Logistic regression analysis showed that the only independently significant variable was obtained on treatment with P2AM, with an odds ratio of $9.2(P<0.006)$. Age also had a significant effect on the outcome. These studies concluded that P2AM has no role in the routine management of patients with OP poisoning.

Scott ${ }^{[65]}$ reported repeated cardiac asystole following P2AM in OP poisoning. A high dose of oximes can produce muscle weakness. ${ }^{[66]}$

In a more recent placebo-controlled study done by us, ${ }^{[67]}$ we used the highest dose of P2AM, as one of the major criticisms was inadequate dose in the previous studies (12 g per day for 3 days for severe cases and $4 \mathrm{~g}$ per day for 3 days for moderate cases). It was shown that butyryl cholinesterase (BuCHE) did not correlate with the severity of poisoning, Type-I or Type-II paralysis, or other complications (Table 3). It also did not differ in cases and controls. The number of days and the total dose of atropine showed no difference in the two groups. BuCHE levels increased gradually over days in both groups and there was no difference whether patients were treated with P2AM or not. The mortality also was similar in both the groups and treatment made no difference- - only two patients died, both in the severe group, and they both died of severe nosocomial infections associated with ventilation.

Thus, use of oximes in OP poisoning remains conflict-
Table 2: Dose-response relationship

\begin{tabular}{lllll}
\hline & Placebo & $\begin{array}{l}\text { Single } \\
\text { dose 1g IV }\end{array}$ & $\begin{array}{l}\text { High dose 12 } \\
\text { g infusion }\end{array}$ & P value \\
$\begin{array}{l}\text { Survival } \\
\begin{array}{l}\text { Alive } \\
\text { Dead }\end{array}\end{array}$ & $52(94.6)$ & $31(68.2)$ & $67(73.7)$ & \\
$\begin{array}{l}\text { Intermediate } \\
\text { syndrome }\end{array}$ & $3(5.4)$ & $5(13.8)$ & $24(26.3)$ & 0.001 \\
$\begin{array}{l}\text { Yes } \\
\text { No }\end{array}$ & $19(13.8)$ & $13(36.1)$ & $36(61.5)$ & \\
$\begin{array}{l}\text { Infections } \\
\text { Yes }\end{array}$ & $36(64.5)$ & $23(63.9)$ & $23(38.5)$ & 0.004 \\
$\begin{array}{l}\text { No } \\
\text { Ventilation }\end{array}$ & $14(25.4)$ & $10(27.8)$ & $25(43.9)$ & \\
Yes & $41(74.6)$ & $26(72.2)$ & $30(56.1)$ & 0.03 \\
No & $22(40)$ & $61(67)$ & $61(67)$ & \\
\hline & $33(60)$ & $19(52.8)$ & $30(33)$ & 0.005 \\
\hline
\end{tabular}

ing and controversial. From the randomized, controlled trials it appears that they have no effect in moderate and severe poisoning and do more harm than good. Pralidoxime is the weaker of the oximes, is very expensive, and unstable in aqueous solution. The treatment options are anticholinergic drugs and assisted ventilation, which is often needed. Mortality rate will continue to be high as long as the patients are managed in hospitals without assisted ventilatory facilities. These patients should be transferred to a center where a proper ICU facility is available at the earliest. On a national level, a minimum pesticide list with less dangerous pesticides made available, phasing out the WHO Class-I and ClassII pesticides would be helpful. The use of safer pesticides should result in fewer deaths.

\section{References}

1. Eddleston M. Patterns and problems of deliberate self poisoning in the developing world. QJM 2000;93:715-31.

2. Jeyaratnam J. Acute pesticide poisoning, a major health prob-

Table 3: Cholinesterase levels by intervention, Type-I paralysis, Type-II paralysis, complications, and mortality

\begin{tabular}{|c|c|c|c|c|}
\hline Variables & $N$ & $\begin{array}{l}\text { Mean cholinesterase } \\
\text { level }\end{array}$ & SD & $P$ value \\
\hline \multicolumn{5}{|c|}{ Intervention } \\
\hline Placebo & 11 & 713.59 & 827.13 & 0.426 \\
\hline Treatment & 10 & 886.25 & 959.60 & \\
\hline \multicolumn{5}{|c|}{ Type-I paralysis } \\
\hline Yes & 11 & 1287.73 & 923.63 & \\
\hline No & 10 & 254.7 & 359.7 & 0.001 \\
\hline \multicolumn{5}{|c|}{ Type-II paralysis } \\
\hline Yes & 11 & 967.14 & 716.48 & \\
\hline No & 10 & 607.35 & 1025.97 & 0.051 \\
\hline \multicolumn{5}{|c|}{ Complications } \\
\hline Yes & 10 & 1047.85 & 700.54 & \\
\hline No & 11 & 568.68 & 982.63 & 0.024 \\
\hline \multicolumn{5}{|l|}{ Mortality } \\
\hline Alive & 19 & 784.32 & 916.61 & \\
\hline Dead & 2 & 905.00 & 368.40 & 0.670 \\
\hline
\end{tabular}


lem. World Health Stat Q 1990;43:139-45.

3. Cherian AM, Jeyaseelan L, Peter JV, et al. Pralidoxime in the treatment of organophosphorus poisoning-a randomized double blind, placebo controlled trial. INCLEN Monograph Series on Critical International Health Issues No. 7, Dec 1977.

4. Shah AC, Trivedi AM, Viswanath $\mathrm{N}$, et al. Intensive respiratory care service, organization, orientation, system and future. Our experience of management of 288 cases. Assoc Physicians India 1990;38:140-3.

5. Jamil H. Organophosphorus insecticide poisoning. JPMA 1989;39:27-31.

6. Ganesvaran T, Subramaniam S, Mhadevan K. Suicide in a northern town of Sri Lanka. Acta Psychitrica Scandinavia 1984;69:420-5.

7. Milby TH. Prevention and treatment of organophosphate poisoning. JAMA 1971;216:2131-3.

8. Agarwal SB. A clinical, biochemical, neurobehahioral and sociopsychological study of 190 patients admitted to hospital as result of acute oraganophosphorus poisoning. Environ Res 1993;62:63-70.

9. Haddad LM. Organophosphates and other insecticides. In: Haddad LM, Winchester J, editors, Clinical management of poisoning and drug overdose. New York: Saunders; 1990. pp. 107687.

10. Tayler P. Anticholinesterase agents. In: Gilman AG, Goodman LS, Rall TW, Murad F, editors. The pharmacological basis of therapeutics. New York, NY: McMillan: 1985. pp. 110-29.

11. Tafuri J, Roberts J. Organophosphate poisoning. Ann Emerg Med 1987;16:193-202.

12. Karalliedde L, Senanayake N. Acute organophosphorus insecticide poisoning in Sri Lanka. Forensic Sci Int 1988;36:97-100.

13. Bardin PG, Eden SF, Moolman JA, Foden AP, et al. Organophosphate and carbamate poisoning. Arch Intern Med 1994;154:1433-41.

14. Samal KK, Sahu CS. Organophosphorus poisoning and intermediate syndrome. J Assoc Physicians India 1990;38:181-2.

15. Tsao TC, Juang $Y$, Lan $R$, Shieh W, Lee $C$. Respiratory failure of acute organophosphate and carbamate poisoning, Chest 1990;98:631-6.

16. Wadia RS, Sadagopal C, Amin RB, Sardesai HV. Neurological manifestations of organophosphorus insecticide poisoning. $\mathrm{J}$ Neurol Neurosurg Psychiatry 1974;37:841-7.

17. Senanayake N, Karaliedde L. Neurotoxic effects of organophosphorus insecticides and intermediate syndrome. N Engl J Med 1987;316:761-3.

18. De Bleecker H, Vogelaers D, Ceuterick C, et al. Intermediate syndrome due to prolonged parathion poisoning. Acta Neurol Scand 1992;86:421-4.
19. De Bleeker J, Van Den Neucker K, Willems J. The intermediate syndrome in organophosphorus poisoning: presentation of a case and review of literature. Clin Toxicol 1992;30:321-9.

20. Samuel J, Thomas K, Jeyaseelan L, Peter JV, Cherian AM. Incidence of intermediate syndrome in organophosphorus poisoning. Assoc Physicians India 1995;43:321-3.

21. De Bleecker J, Van Den Neucker K, Colardyn F. Intermediate syndrome in organophosphorus poisoning: a prospective study. Crit Care Med 1993;21:1706-11.

22. He F, Xu H, Qin F, Xu L, Huang J, He X. Intermediate myasthenia syndrome following acute organophosphate poisoning-an analysis of 21 cases. Hum Exp Toxicol 1998;17:40-5.

23. Peter S, Alexander M, Jeyaseelan L, Cherian AM. Electrophysiological study in organophosphorus poisoning [thesis]. In press.

24. John M, Zachariah A, Oommen A. Myopathy associated with organophosphorus poisoning[thesis]. In press.

25. Morreto A, Lotti M. Poisoning by organophosphorus insecticides and sensory neuropathy. Neurol Neurosurg Psychiatry 1998;64:463-8.

26. Lotti M, Becker CE, Aminoff MJ. Organophosphate polyneuropathy: pathogenesis and prevention. Neurology 1984;34:64:4638.

27. Senanayake N. Polyneuropathy following insecticide poisoning: a clinical and electrophysiological study. J Neurol 1985; Suppl:203:232.

28. Baker T, Stanec A. Methylprednisolone treatment of an organophosphorus induced delayed neuropathy. Toxicol Appl Pharmacol 1985;79:348-52.

29. Jamal GA. Neurological syndromes of organophosphorus compounds. Adverse Drug React Toxicol Rev 1997;16:133-70.

30. Senanayake N, Sanmughanathan PS. Extrapyramidal manifestations complicating organophosphorus insecticide poisoning. Hum Exp Toxicol 1995;14:600-4.

31. Ishikawa S, Miyata M, Aoki S, Hanai Y. Chronic intoxication of organophosphorus pesticide and its treatment. Abstract Folia Med Cracow 1993;34:139-51.

32. Adlakha A, Philip PJ, Dhar KL. Guillain Barre Syndrome sequela of organophosphorus poisoning. Assoc Physicians India 1987;35:665-6.

33. Patil RK ,Bansal SK, Sehgal VK, Chander B. Shincteric involvement in organophosphorus poisoning. Assoc Physicians India 1991;39:492-3.

34. De Silva HJ, Sanmuganathan PS, Senanayake N. Isolated bilateral laryngeal nerve paralysis: a delayed complication of organophosphorus poisoning. Hum Exp Toxicol 1994;13:171-3.

35. Ernest K, Thoma M, Poulose M, Rupa V, Gnanamuthu C. Delayed effects of exposure to organophosphorus compounds. Ind 
J Med Res 1995;101:81-4.

36. Saadeh AM, Farrakhan M, Ali-Ali MK. Cardiac manifestations of acute carbamate and organophosphorus poisoning. Heart 1997;77:461-4.

37. Ludomirsky A, Klein H, Sarelli P, Becker B, Hoffman S, Taitelman $\mathrm{U}$, et al. Q-T prolongation and polymorphic (torsade de pointes) ventricular arrhythmias associated with organophosphorus poisoning. Am J Cardiol 1982;49:1654-8.

38. Kiss Z, Fazekas T. Arrythmias in organophosphorus insecticide poisonings. Acta Cardiol 1979;34:323-30.

39. Chuang FR, Jang SW, Lin JL, Chern MS, Chen JB, Hu KT. QTC prolongation indicates a poor prognosis in patients with organophosphorus poisoning. Am J Emerg Med 1996;14:451-3.

40. Martin Rubi JC, Yelamus RF, Laynex BF, et al. Poisoning caused by organophosphate insecticides; study of 506 cases (abstract). Rev Clin Exp 1996;196:145-9.

41. Moore PG, James OF. Acute pancreatitis induced by acute organophosphorus poisoning. Postgrad Med J 1981;57:600-62.

42. Meller D, Fraser I, Kryger M. Hyperglycaemia in anticholinesterase poisoning. Can Med Assoc J 1981;124:745-8.

43. Mambas T, Nolte CT, Jackrel J, Grob D. Poisoning due to organophosphorus insecticides. Am J Med 1971;50:475-92.

44. Bardin PG, Van Eden SF. Organophosphate poisoning: grading the severity and comparing treatment between atropine and glycopyrrolate. Crit Care Med 1990;18:956-60.

45. Bobba R, Venkataraman BV, Pais P, Joseph T. Correlation between the severity of symptoms in organophosphorus poisoning and cholinesterase activity (RBC and plasma) in humans. Ind J Physiology Pharm 1996;40:249-52.

46. Matchevich VA, Simonenkov AP, Ostapenko IN, Zavadovskii MM, Drendel SD, Kashtanova IS. Use of serotonin adipinate in acute oral poisoning. Abstract Anesteziol Reanimatol 1995;3:16-20.

47. Ram JS, Kumar SS, Jeyarajan A, Kuppuswami G. Continous infusion of high dose of atropine in the management of organophosphorus poisoning. Assoc Physicians India 1991;39:190-3.

48. Cherian AM, Peter JV, Samuel J, Jeydevan R, Peter S, Joel S, et al. Effectiveness of P2AM in the treatment of organophosphorus poisoning. A randomized, double blind placebo controlled clinical trial. Assoc Physicians India 1997;45:22-4.

49. Namba T. Cholinesterase inhibition by organophosphorus compounds and its clinical effects. Bull WHO 1971;44:289-307.

50. Durham WF, Wayland JH. Organic phosphorus poisoning and its therapy. Arch Environ Health 1962;5:27-47.

51. De Silva HJ, Wijewickrema R, Senanayake N, et al. Does pralidoxime affect outcome of management in acute organophosphorus poisoning. Lancet 1992;339:1136-8.

52. Thiemann H, Mast U, Klimmek R, et al. Cholinesterase status, pharmacokinetics and laboratory findings during obidoxime therapy in organophosphate poisoned patients. Hum Exp Toxicol 1997;16:473-80.

53. Wrek F, Reiter G, Eyer P, et al. Reactivation kinetics of acetyl cholinesterase from different species inhibited by highly toxic organophosphates. Arch Toxicol 2002;76:523-9.

54. Worek F, Backer M, Thiermann H, et al. Reappraisal of indications and limitations of oxime therapy in organophosphate poisoning. Hum Exp Toxicol 1997;16:466-72.

55. Worek F, Diepold C, Eyer P. Dimethylphodphoryl-inhibited human cholinesterase: inhibition, reactivation and aging kinetics. Arch Toxicol 1999;73:7-14.

56. Worek F, Eyer P, Szinicz L. Inhibition, reactivation and aging kinetics .of cyclohexylmethylphosphonoflouridate-inhibited cholinesterase. Arch Toxicol 1998;72:580-7

57. Eyer $\mathrm{P}$, Hell W, Kawan A, et al. Studies on the decomposition of oxime HI6 in aqueous solution. Arch Toxicol 1986;59:266-71.

58. Khan S, Hemalatha R, Jeyaselan L, et al. Neuroparalysis and oxime efficacy in organophosphate poisoning. A study of butyrylcholinesterase. Hum Exp Toxicol 2001;20:169-74.

59. Eyer $\mathrm{P}$, Kawan A, Ladstetter B. Formation of cyanide after i.v. administration of oxime HI6 to dogs. Arch Toxicol 1987;61:63-9.

60. Johnson S, Peter JV, Thomas K, Jeyaseelan L, Cherian AM. Evaluation of two treatment regimens of pralidoxime $(1 \mathrm{gm}$ single bolus dose vs $12 \mathrm{gm}$ infusion) in the management of organophosphorus poisoning. J Assoc Physicians India 1996;44:52931.

61. Eddlestone M, Szinicx L, Eyer P, et al. Oximes in acute organophosphorus poisoning: a systematic review of clinical trials. QJM 2002;95:275-83.

62. Balali-Mood M, Shariat M. Treatment of acute organophosphate poisoning. Experince of nerve agents and acute pesticide poisoning on the effects of oximes. Abstract $J$ Physiol Paris 1998;92:375-8.

63. Abdollahi $\mathrm{M}$, Jafari $\mathrm{A}$, Jalali $\mathrm{N}$, et al. A new approach of efficacy of oximes in the management of organophosphate poisoning. Iranian J Med Sci 1995;20:105-9.

64. Mathew CA, Johnson S, Anand R, Roshini C, Peter JV, Jeyaseelan L, et al. Usefulness of Oximes in acute organophosphorus poisoning. Int Med J, In press.

65. Scott RJ. Repeated asystole following PAM in organophosphate self poisoning. Anaesth Intensive Care 1986;14:458.

66. Taylor P. Anticholinesterase agents. In: Gilman AG, Goodman LS, Rall TW, Murad F, editors. The pharmacological basis of therapeutics. New York,NY: MacMillan 1985;122.

67. Mathew CA, Roshini C, Visalakshi J, Jeyaseelan J, Cherian AM. Biochemical and clinical profile after orgnophosphorus poisoning - a placebo controlled trial using P2AM. J Assoc Physicians India 2005;53:427-31. 